\title{
含半夹心铱/铑/钉结构基元的离散型金属环状化合物的研究进展
}

\author{
刘金宝*, $a$ 李 鹏 $a, b$ 姚子健*, $a, b$ \\ $\left({ }^{a}\right.$ 上海城建职业学院 上海 201415) \\ ${ }^{b}$ 上海应用技术大学化学与环境工程学院 上海 201418)
}

\begin{abstract}
摘要 由于离散型金属环状化合物在主客体化学、气体吸附、分子识别及催化等领域被广泛应用, 因此, 构筑新型金 属环状化合物并研究它们的物理化学性质及应用成为无机化学、有机化学和超分子化学中热门研究方向之一. 具有半 夹心结构的钉、铱和铑有机金属单元在形成金属环状化合物时具有以下的优势: 增强了化合物的溶解性，屏蔽住金属 的一半以减少反应的复杂性，易于修饰得到不同结构的产物. 综述了近年来以半夹心结构的钉、铱和铑结构基元的离 散型金属框架化合物的组装合成和应用.
\end{abstract}

关键词 有机金属; 半夹心; 铱/铑/钉; 金属大环

\section{Recent Progress of Discrete Metallacycles Based on the Half-Sandwich Ir/Rh/Ru Motifs}

\author{
Liu, Jinbao $^{a} \quad$ Li, Peng ${ }^{a, b} \quad$ Yao, Zijian ${ }^{*, a, b}$ \\ ( ${ }^{a}$ Department of Science and Technology, Shanghai Urban Construction Vocational College, Shanghai 201415) \\ $\left({ }^{b}\right.$ School of Chemical and Environmental Engineering, Shanghai Institute of Technology, Shanghai 201418)
}

\begin{abstract}
Discrete metallacycle complexes have attracted considerable attention because of their widely used in host-guest chemistry, gas adsorption, molecular recognition and catalysis. Thus exploring new framework complexes, studying their physical and chemical properties and applications have become one of the most active and exciting areas of inorganic chemistry, organic chemistry and supramolecular chemistry. Half-sandwich organometallic units based on ruthenium, iridium and rhodium are often utilized to prepare diverse metallacylce complexes due to the following advantages: the solubility of these metal complexes can be enhanced, the hemisphere of the metal center is perfectly shielded, minimizing the complexity of reactions, and the products with different structures are easily synthesized. In this paper, the synthesis and application of discrete type metal framework complexes with half-sandwich structures of ruthenium, iridium and rhodium are reviewed.

Keywords organometallic; half-sandwich; $\mathrm{Ir} / \mathrm{Rh} / \mathrm{Ru}$; metallacycle
\end{abstract}

近几十年来, 具有有限结构的离散型配位超分子化 合物作为一种新型多孔材料引起人们的广泛关注 ${ }^{[1 \sim 5]}$. 这类化合物由金属离子和有机配体共同构成, 包括不含 $\mathrm{M}-\mathrm{C}$ 键金属一有机框架化合物和含有 $\mathrm{M}-\mathrm{C}$ 键有机金 属框架化合物. 与合成具有无限结构的金属-有机骨架 型化合物需要尽量利用金属中心的多配位点不同, 要合 成得到具有有限结构的离散型有机金属框架化合物需 要有目的地控制金属中心的配位数和配位方向. 这种有 机金属框架化合物由金属和有机配体作为构筑单元 (building block), 利用配位键和分子间弱的相互作用,
通过分子自组装的方式有机结合起来而形成一类具有 规则结构的超分子化合物. 它们在主客体化学、分子识 别、气体吸附、催化化学以及纳米化学等领域具有广泛 应用 ${ }^{[6 ~ 12]}$. 这类化合物与冠醚、环糊精等环状结构相比

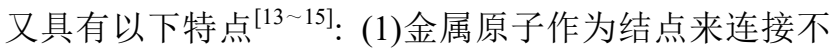
同有机配体, 从而形成构筑单位, 而冠醚和环糊精类化 合物都是由单一的构筑单元来构筑; (2)这类化合物不仅 可以由单一组分构成, 还可以根据需要来选择不同的配 体合成多组分目标化合物; (3)它可以利用对金属角的修 饰来形成不同的空间构造，可以成环，可以成柱状，可

\footnotetext{
*Corresponding authors. E-mail: hgliujinbao@163.com, zjyao@sit.edu.cn Received August 5, 2019; revised September 17, 2019; published online October 9, 2019 Project supported by the National Natural Science Foundation of China (No. 21601125), the Chenguang Scholar of Shanghai Municipal Education Commission (Nos. 16CG64, 18CGB12).

国家自然科学基金(No. 21601125)、上海市晨光计划(Nos. 16CG64, 18CGB12)资助项目.
} 
以成笼, 甚至是环环相扣的连锁状化合物. 因此, 构筑 新型的框架化合物, 并研究它们的物理化学性质及应用 逐渐成为无机化学、有机化学和超分子化学中的热门研 究领域之一.

20 世纪 90 年代, Fujita 等 ${ }^{[16]}$ 以金属钯作为金属角, 4,4-联吡啶为有机配体, 通过 $\mathrm{N}$ 原子与金属配位构筑了 首例四边形有机金属框架化合物，由此拉开了以金属为 角的合成多边形有机金属化合物的序幕. 随后，Stang 等 ${ }^{[17]}$ 通过改变有机配体得到了结构多样的框架化合物. 他们总结规律发现: 通过改变配体配位的取向的角度和 金属角的角度可以可控地制备具有特定二维平面或三 维立体结构的有机金属大环化合物. 随后, Wilson 等 ${ }^{[18]}$ 以金属铑为金属角合成了一系列具有半夹心结构的有 机金属框架化合物. 从此, 以具有半夹心结构的钓、铱 和铑构建有机金属框架化合物进入了科学家的视线. 对 比其它金属单元, 科学家们发现具有半夹心结构的钉、 铱和铑有机金属单元在形成有机金属框架化合物时具 有以下优势 ${ }^{[19 ~ 23]}$ (图 1): (1)反应的原料如[( $p$-cymene)$\left.\mathrm{RuCl}_{2}\right]_{2}$ 或 $\left[\mathrm{Cp}^{*} \mathrm{MCl}_{2}\right]_{2}\left(\mathrm{Cp} *=\eta^{5}-\mathrm{C}_{5} \mathrm{Me}_{5}, \mathrm{M}=\mathrm{Ir}\right.$ 或 $\left.\mathrm{Rh}\right)$ 较 容易制备且产率高, 在有机金属化合物中具有较高稳定 性; 另外由于茂环的对称性, 使得这类化合物易于结晶, 便于我们从分子层面对其进行结构分析. (2)原料在常用 有机溶剂中具有良好的溶解度, 在水中也可以溶解, 为 研究此类化合物的后续应用提供了便利的条件. (3)通过 改变配体的取代基, 可以改变自组装结构的溶解性及氧 化还原性. (4)六配位金属 $(\mathrm{Ru}(\mathrm{II}) 、 \operatorname{Ir}(\mathrm{III})$ 和 $\mathrm{Rh}(\mathrm{III}))$ 一半配 位点为 $\pi$-配体屏蔽, 有利于定向成键. (5)含有半夹心结 构有机金属 $\mathrm{Ru} 、 \mathrm{Ir}$ 或 $\mathrm{Rh}$ 的化合物在有机合成和催化，以 及光学性质方面具有较高的应用前景, 有利于开展目标 化合物的实际应用研究.

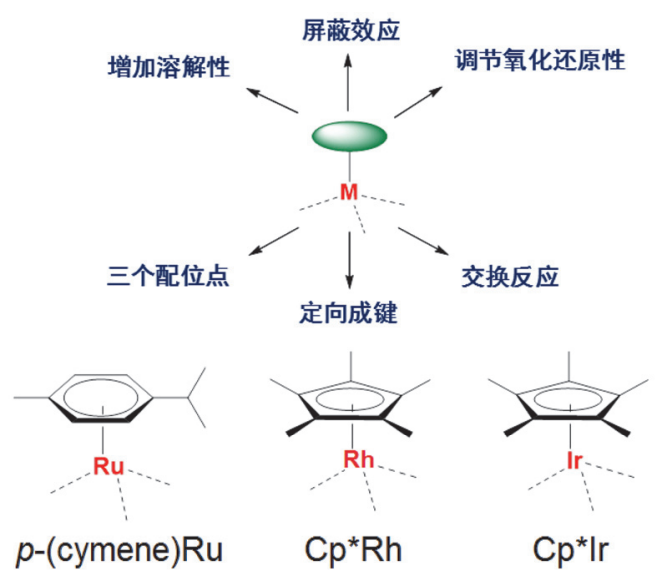

图 1 半夹心有机金属化合物及其性质

Figure 1 Structure and property of half-sandwich complexes

由于上述列举出的独特优势, 国内外多个课题组对
这一结构在有机金属框架化合物中的构筑和应用进行 探索.他们利用不同的双核有机金属分子夹，用银盐拔 去金属上的氯离子, 然后将其与双齿桥联配体 $[2+2]$ 自 组装，或与三齿桥联配体 $[3+2]$ 自组装，或与四齿桥联 配体 [4+2]自组装，构筑了具有不同形状、不同尺寸的 有机金属框架化合物(图 2), 例如具有 2-D 平面结构的 三核和四核配合物，具有 3-D 立体结构的六核和八核配 合物，以及具有互锁交扣结构的多核配合物. 本文以不 同形状的有机金属框架化合物为主线, 对含有半夹心结 构钉、铱和铑有机金属框架化合物的研究进展进行系统 性综述.

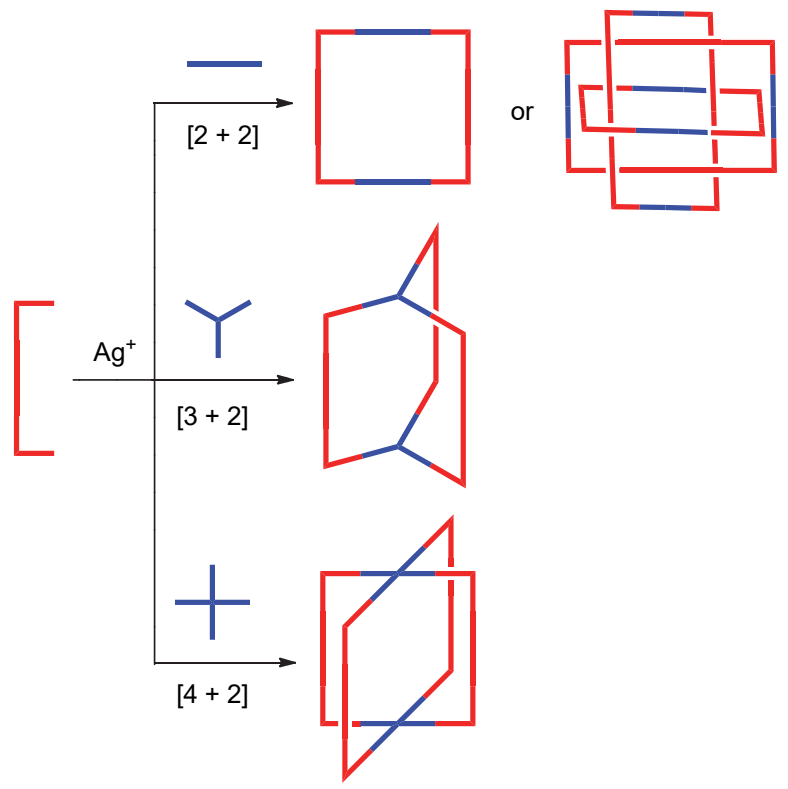

图 2 金属大环框架化合物的自组装

Figure 2 Self-assembly of metallacycle complexes

\section{2-D 平面}

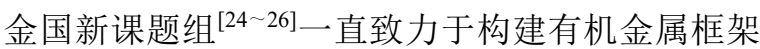
化合物的研究, 并取得了一系列出色的成果. 他们用草 酸作为桥梁配体设计双核的半夹心金属(钉、铑或铱)配 合物的分子夹 $(\mathbf{A 1} \sim \mathrm{A} 3)$, 然后与直线型双齿含氮配体 $(\mathbf{L 1} \sim \mathbf{L 3})$ 通过 [2+2]自组装得到一系列二维平面结构的 四核矩形框架配合物(图 3). 这些金属配合物中吡啶基 桥梁金属与金属的距离在 0.69 与 $1.35 \mathrm{~nm}$ 之间 ${ }^{[27]}$. 另外, 草酸桥联双金属分子夹中构筑的大环框架化合物在模 板控制的光化学反应方面有巨大的应用价值 ${ }^{[28]}$.

随后，他们用氯醌酸 $(\mathbf{B} 1)$ 和二氢蒽醌 $(\mathbf{C})$ 作为桥联 配体构建双核金属分子夹，增大分子夹中金属与金属间 的距离, 然后与直线型双齿含氮配体自组装四核有机金 属框架配合物. 这些框架配合物都具有较大的空腔, 可 以容纳一些客体分子，例如乙醚、二氯甲烷及甲醇等 

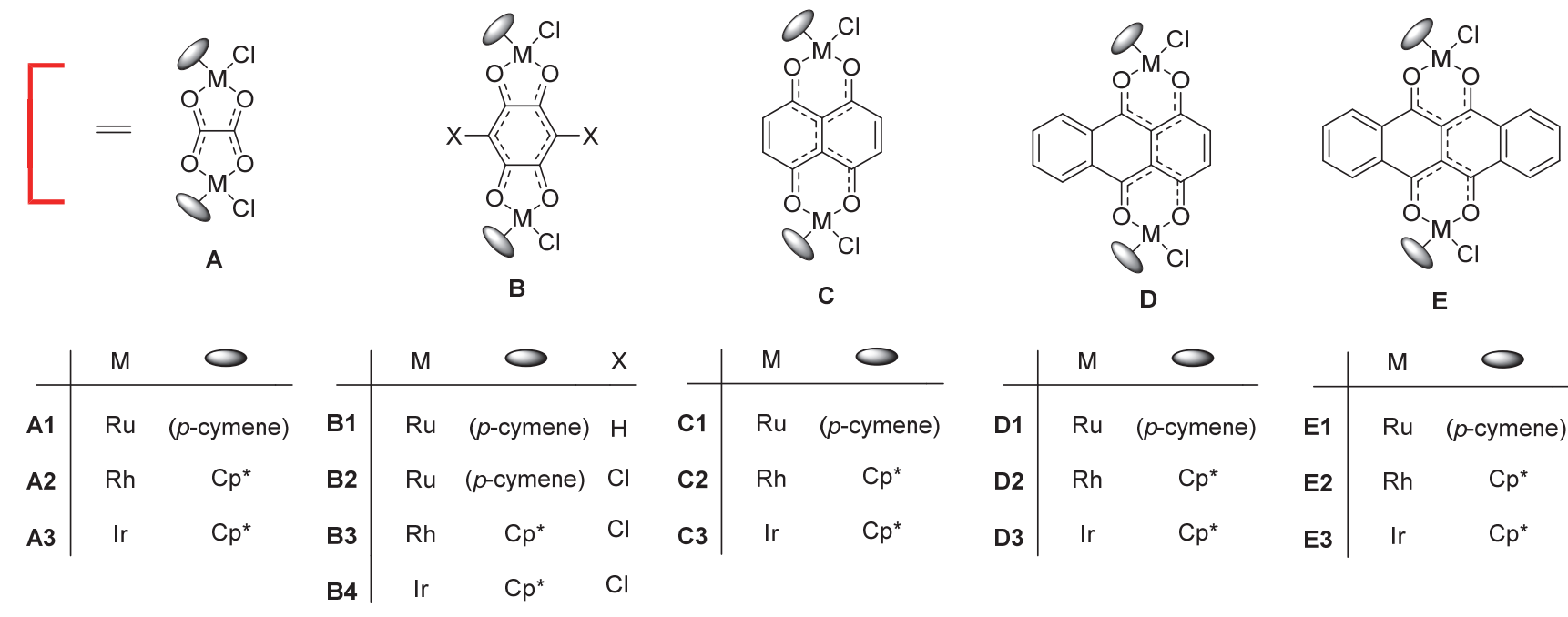<smiles>c1cnccn1</smiles>

L1<smiles>c1cc(-c2ccncc2)ccn1</smiles>

L2

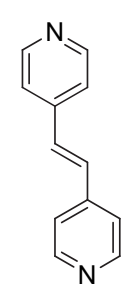

L3<smiles>C(#Cc1ccncc1)c1ccncc1</smiles>

L4<smiles>c1cc(-c2ccc(-c3ccncc3)cc2)ccn1</smiles>

L5
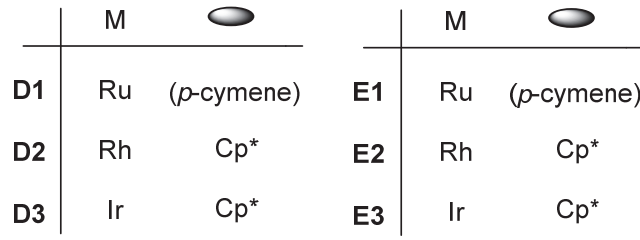

图 3 不同桥联配体的双金属分子夹

Figure 3 Binuclear metal clips with different bridge ligands

分子 ${ }^{[29 ~ 32]}$. 其中, 以 6,11-二羟基-5,12-萘并萗二酮(D)和 吡嗪(L1)作为桥联配体构筑的四核矩形框架化合物可 以选择性吸收容纳二氯甲烷分子 ${ }^{[29]}$. 这为大环有机金 属框架化合物用于气体选择性吸附提供了理论依据. 2018 年, 他们 ${ }^{[33]}$ 用四吡啶并吩嗪作为桥梁配体合成双 金属(铱或铑)分子夹, 与双齿含氮配体通过 $[2+2]$ 自组
装构筑四核矩形框架配合物(图 4). 这个四核矩形框架 配合物具有大的空腔，通过 $\pi-\pi *$ 堆积相互作用，可以容 纳两个晕苯分子.

受金属钉配合物可以选择性抗癌细胞转移的启 发 ${ }^{[34 ~ 36]}$, Therrien 课题组 ${ }^{[37,38]}$ 基于金属钉构建了大量大 环金属配合物. 他们以 2,5-二羟基-1,4-苯醌(B)作为桥联

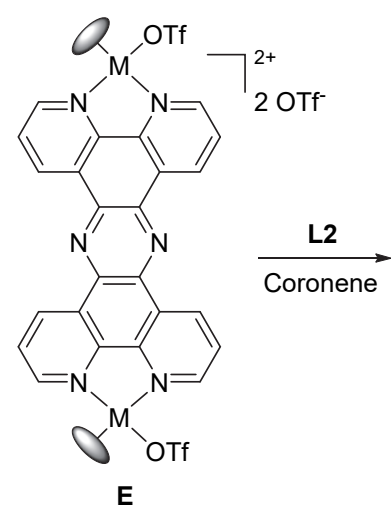

E

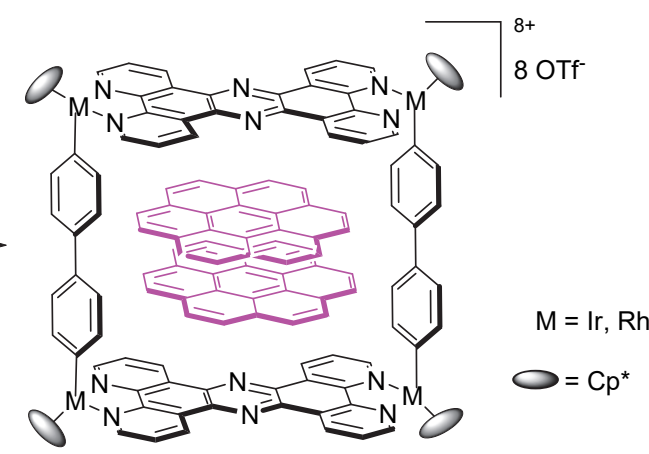

图 4 四核矩形框架化合物的合成

Figure 4 Synthesis of tetra-nuclear metallacycles

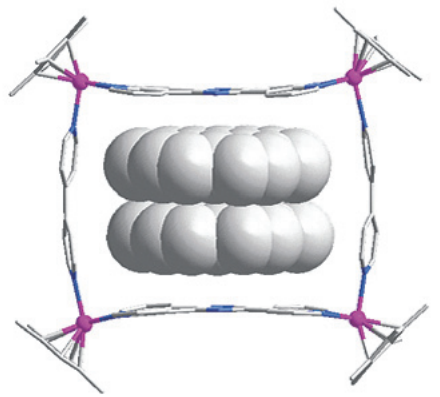


配体合成双金属钉分子夹, 以 4,4'-联吡啶(L2)和 1,2-双(4-吡啶基)乙烯 (L3) 作为双齿配体构筑四核矩形金属钉 配合物(图 5). 这些配合物在体外可以展现出细胞毒性 对抗卵巢癌细胞 ${ }^{[39]}$. 随后, Therrien 等 ${ }^{[40]}$ 以 5,8-二差基1,4 -菜醌 $(\mathbf{C})$ 和含氮双齿配体 $(\mathbf{L} \mathbf{L} \sim \mathbf{L} 3)$ 作为桥联配体构 建了半夹心结构的铱和铑有机金属框架化合物. 这些框 架化合物在体外可以对卵巢癌细胞(A2780)和人胚肾细 胞展现出高的细胞毒性. 这一结果进一步证实了金属框 架化合物在生物学领域的巨大应用潜力.

构建异核金属框架配合物一直是科学家的研究兴 趣之一. 金国新等 ${ }^{[41]}$ 先用三联吡啶与二价铜、锌、镍等 金属配位形成双配位点的吡啶基配体(L9), 然后与双金 属铑、铱分子夹 $(\mathbf{E})$ 通过 $[2+2]$ 自组装构建四核异金属矩 形框架配合物(图 6). 2016 年, Chi 课题组 ${ }^{[42]}$ 基于具有三 明治结构的钴配合物开发含氮双齿配体 (L10), 与草酸 类衍生物 $(\mathbf{A})$ 和半夹心金属钉自组装构建四核异金属矩 形框架配合物. 得益于金属钴和钉都有很好的生物抗癌 活性, 这些包含双金属的框架化合物对胃癌细胞具有高 的细胞毒性, 能够诱导胃癌细胞自噬调亡, 为抗胃癌药 物的开发提供了新的思路(图 7).

Lee 等 ${ }^{[43]}$ 创新性的基于氟硼二吡咯类染料(BODIPY)开发含氮双齿配体(L11)(图 8), 与含半夹心结构的 双核金属钌、铱分子夹通过 $[2+2]$ 自组装构筑四核矩形 金属框架化合物(图9). 通过生物学笁选, 这些配合物对

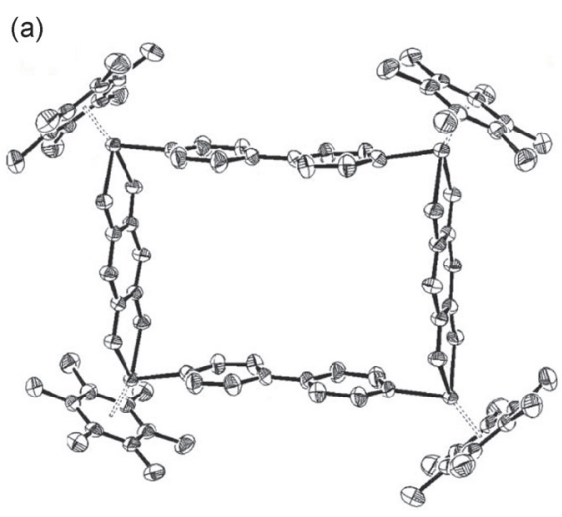

MCF-7 和 U87 细胞展现出比顺铂更好的细胞毒性. 随 后，他们发现：当在氟硼二吡咯与吡啶之间加入噻吩基 团后(L12), 所得的四核金属矩形框架化合物显示出对 乳腺癌细胞选择性抗增殖活性 ${ }^{[44]}$. 而且, 这些化合物对 DNA 和蛋白质都有一定程度的相互作用, 这为以后基 于 BODIPY 开发金属框架化合物以提高生物活性提供 了新的思路.

\section{3-D 立体}

构筑三棱柱形和立方形等三维立体结构的超分子 配合物也一直研究热点之一. 金国新课题组 ${ }^{[45 \sim 48]}$ 利用 草酸 $(A)$ 、氯醌酸 $(\mathbf{B})$ 和二氢蒽醌衍生物 $(\mathbf{C})$ 作为桥梁配体 合成双核的半夹心金属(钉、铑或铱)配合物的分子夹， 然后在三氟甲基磺酸银的存在下与三齿含氮配体 2,4,6三-(4-吡啶基)-1,3,5-三嗪(TPT) (L13)通过[3+2]自组装 得到三棱柱笼状结构的六核金属配合物(图 10 和图 11). 这些大环笼状金属配合物通过 $\pi-\pi *$ 相互作用，可以作为 主体包含一些芳香族类客体分子, 例如萠、晕苯和六甲 氧基三亚苯基，形成主客体体系. 随后，他们合成一系 列席夫碱类配体, 利用金属诱导的碳氢键活化, 与 $\mathbf{L 1 3}$ 通过 $[3+2]$ 自组装构筑笼状结构的六核金属配合物. 在 没有客体分子进入笼状结构时，两个三嗪分子中心距离 大约只有 $0.33 \mathrm{~nm}$. 但是, 当客体分子进入笼状结构后, 两个三嗪分子中心距离增大到 $0.66 \mathrm{~nm}$ 左右 ${ }^{[49,50]}$.

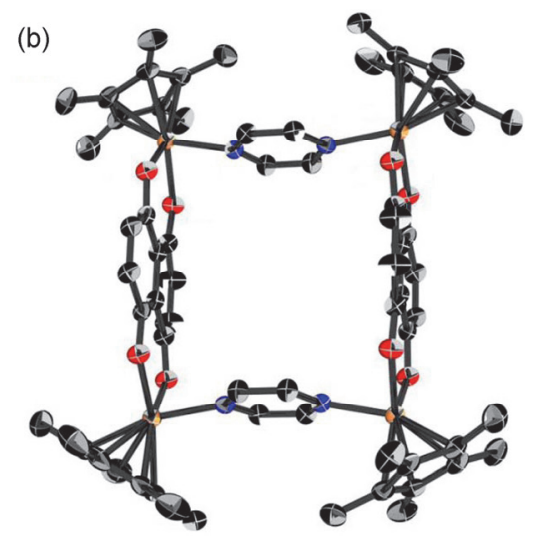

图 5 含半夹心钉金属环状化合物

Figure 5 Metallacycles based on half-sandwich Ru motif
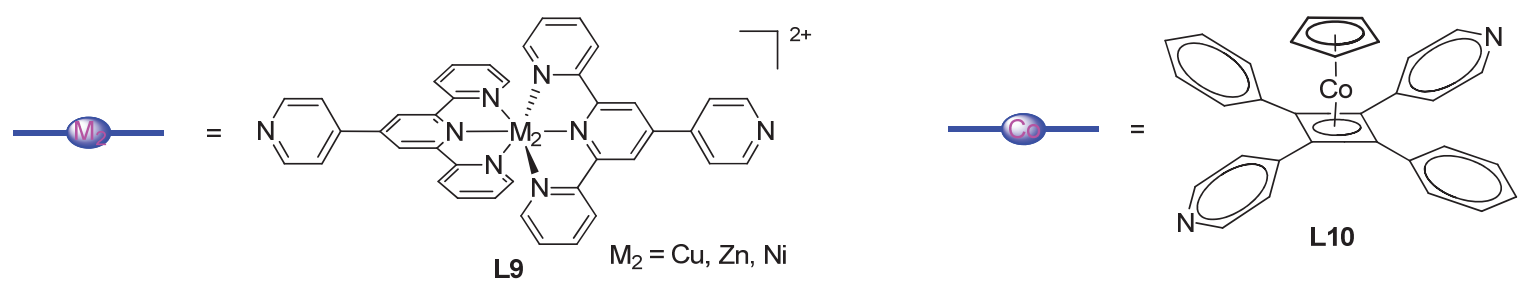

图 6 含杂原子的双齿含氮桥联配体

Figure 6 Bidentate bridge ligands with heteroatoms 


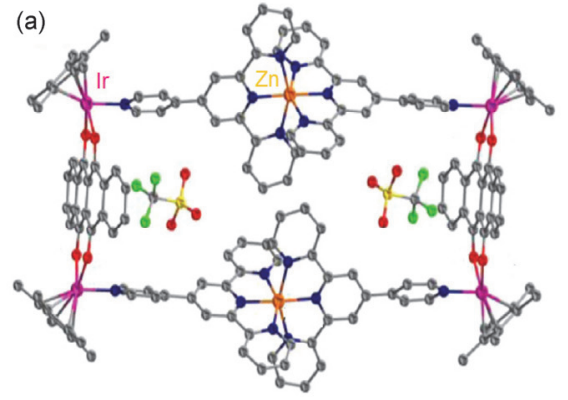

(b)
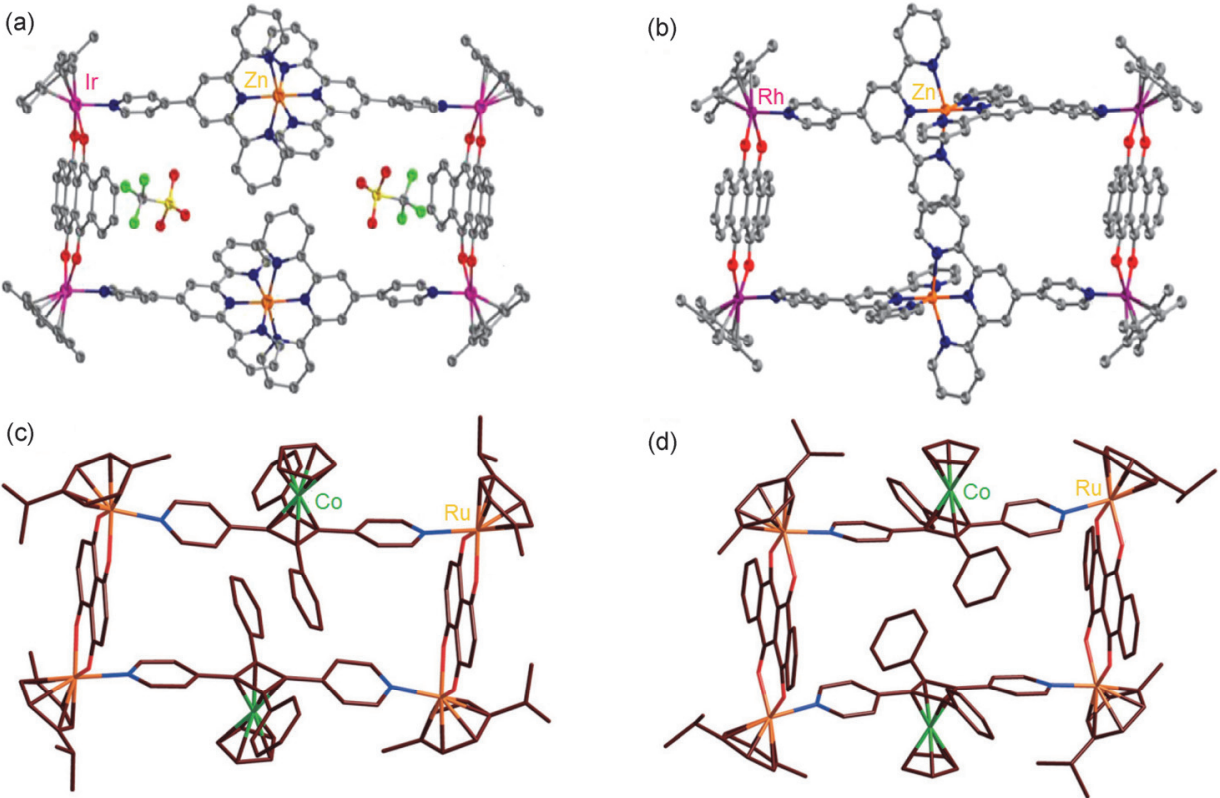

图 7 异核矩形框架化合物单晶结构

Figure 7 Single crystals of heteronuclear metallacycles

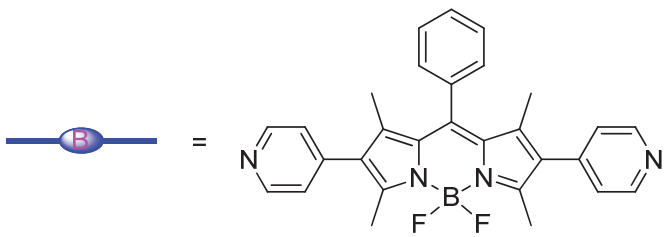

L11

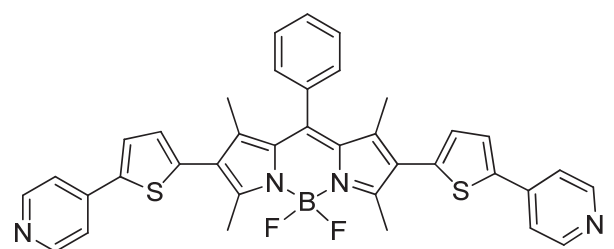

L12

图 8 含 BODIPY 的双齿含氮桥联配体

Figure 8 Bidentate bridge ligands with BODIPY

(a)

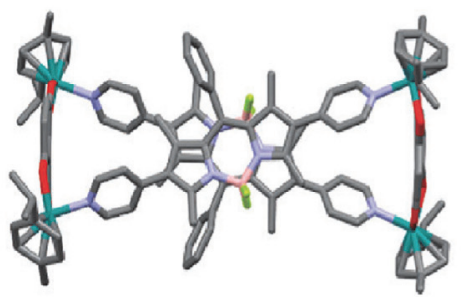

(c)

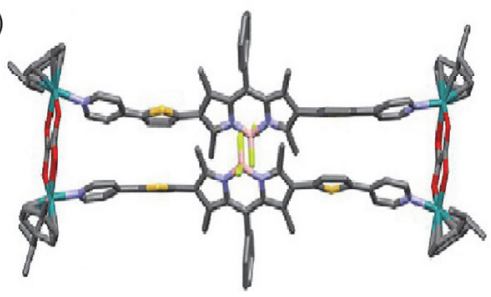

(b)

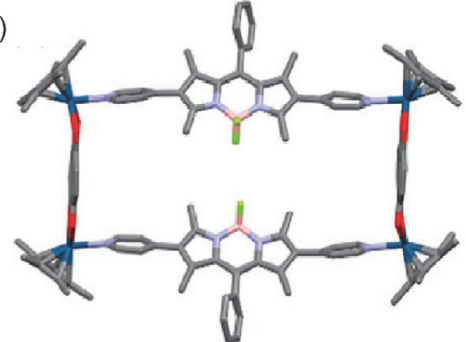

(d)

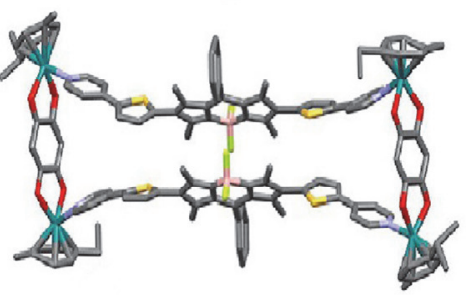

图 9 含 BODIPY 矩形框架化合物的单晶结构

Figure 9 Single crystals of metallacycles with BODIPY

2008 年, Therrien 等 ${ }^{[51]}$ 首先用三棱柱形钉金属框架 化合物作为载体用于药物输送系统. 他们用 2,5 -二羟基1,4-苯醌 (B)作为桥梁配体构建双金属钉的分子夹, 然后 在三氟甲基磺酸银的存在下与三齿含氮配体 TPT (L13)
通过 $[2+3]$ 自组装得到三棱柱笼状结构的六核金属框架 配合物(图 12). 而当双核钉金属分子夹在在三氟甲基磺 酸银的存在下与三齿含氮配体 TPT 自组装时有乙酰丙 酮铂(或钯)络合物存在, 反应产率并没有改变, 且形成 


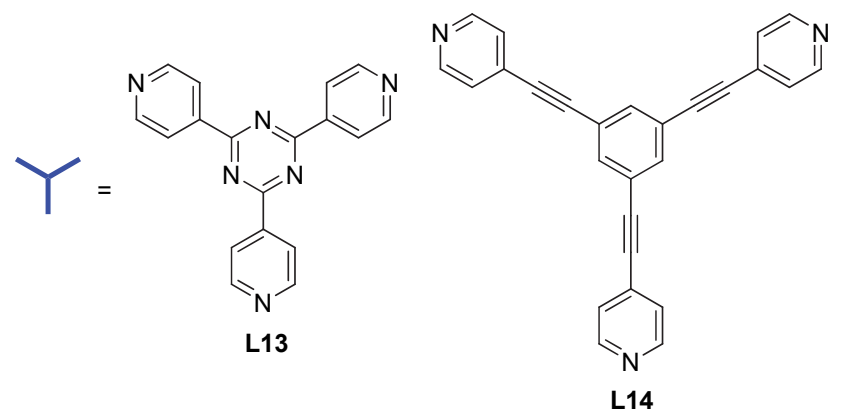

图 10 三齿含氮桥联配体

Figure 10 Tridentate bridge ligands with $\mathrm{N}$ atom
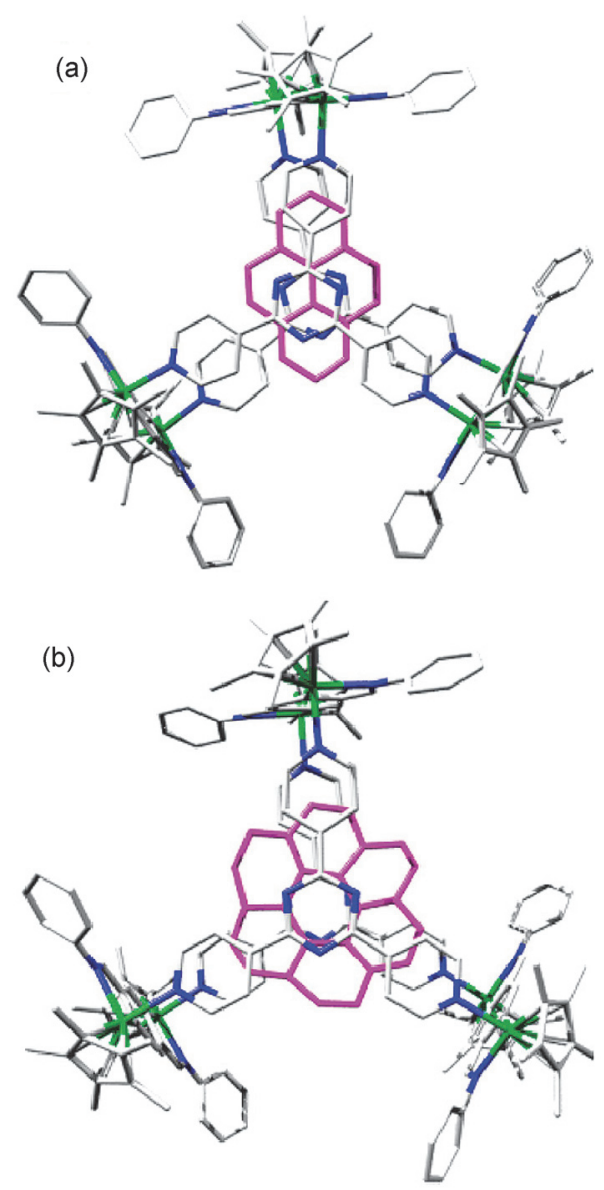

图 11 三棱柱形框架化合物的单晶结构

Figure 11 Single crystal of triangular prism metallacycles

了 Complex-in-Complex 复合物. 这个三棱柱状的六核金 属框架配合物对人卵巢 $\mathrm{A} 2780$ 癌细胞的 $\mathrm{IC}_{50}$ 浓度为 23 $\mu \mathrm{mol} / \mathrm{L}$, 而当乙酰丙酮铂络合物被包纳在笼子里时, 对 $\mathrm{A} 2780$ 癌细胞的 $\mathrm{IC}_{50}$ 浓度仅为 $1 \mu \mathrm{mol} / \mathrm{L}$.

随后, Therrien 课题组 ${ }^{[52 ~ 56]}$ 一直探索怎样通过增大 金属笼或客体的分子量, 以增强钓金属框架配合物携带 客体药物分子进入癌细胞的渗透性和保留时长(EPR effect). 他们基于萠合成了一系列萠基官能团化的化合 物作为客体分子封闭在钉金属框架化合物中形成复合 物(图 13,a, b, c). 这些复合物中的芘基包含在笼状六核
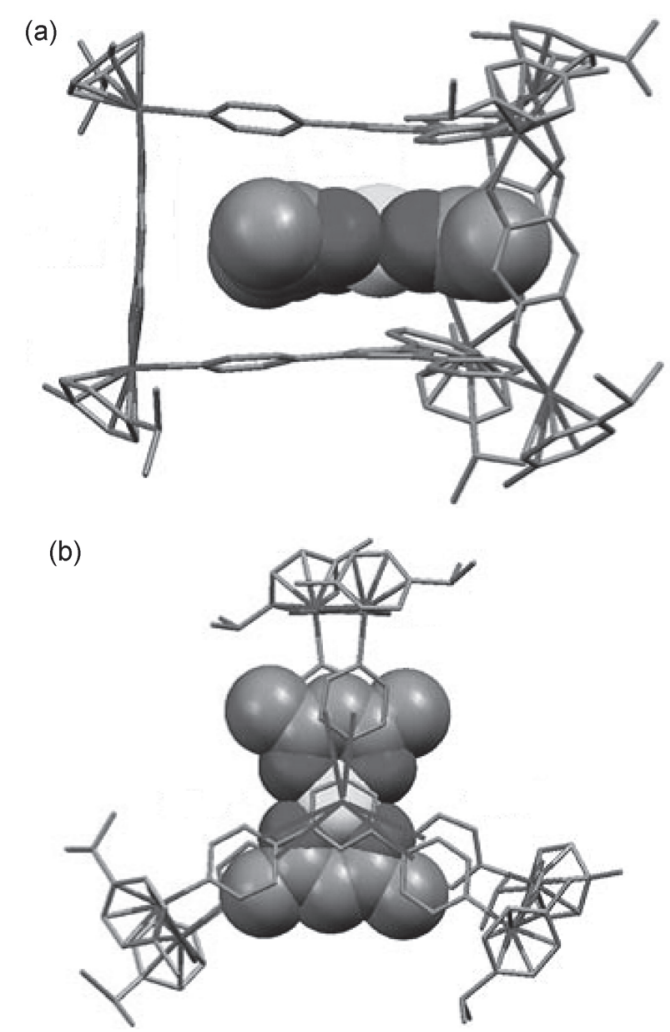

图 12 六核金属大环化合物的单晶结构

Figure 12 Single crystal of hexa-nuclear metallacycles

金属钉框架化合物中，而对癌细胞起作用的官能化基团 暴露在外, 以此达到治疗目的. 随后, 他们尝试增加主 体笼的分子量以增强 EPR 效应. 他们将双核金属钓分 子夹的桥梁配体烷基化, 增长碳链以加大分子量 ${ }^{[57,58]}$ (图 13, d, e, f). 但是由于烷基链的疏水性，隐藏在金属 笼中, 堵塞了用于客体分子传送的通道, 未达到理想的 结果.

Chi 课题组 ${ }^{[59 ~ 65]}$ 在构筑三棱柱形立体的超分子配合 物方面也做了大量出色的工作. 他们主要以含氮三齿配 体 1,3,5-三吡啶基-(4-乙炔基)苯(L14)作为桥梁配体构筑 三棱柱状六核金属钓配合物, 并测试其对癌细胞的抗癌 活性. 他们发现当以 5,8-二羟基-1,4-荎醌(C)作为桥梁配 体构建双金属钉分子夹，与 $\mathbf{L 1 4}$ 通过[3+2]自组装构筑 的六核金属钓配合物对癌细胞 HeLa, HCT-15 和 A549 都 具有比顺铂更低的 $\mathrm{IC}_{50}$ 值 ${ }^{[60,61]}$. 随后，他们构筑了多种 多样的笼状金属配合物作为主体，通过 $\pi-\pi^{*}$ 相互作用吸 收客体进入, 形成主客体体系. 最具代表性的是利用 1,4-双-(二吡咯甲基)-苯作为桥联配体构建的双核铱金 属分子夹. 这个双核铱金属分子夹中金属与金属的距离 达到 $1.2623 \mathrm{~nm}$, 大约是 4 倍 $\pi-\pi *$ 堆积的距离. 由这个分 子夹和 TPT (L13)通过 $[3+2]$ 自组装得到三棱柱笼状结 构的六核金属铱配合物可以作为主体容纳三个芳香族 平面客体, 包括两分子晕苯和一分子 $N, N^{\prime}$-二甲基- 1,4 , 

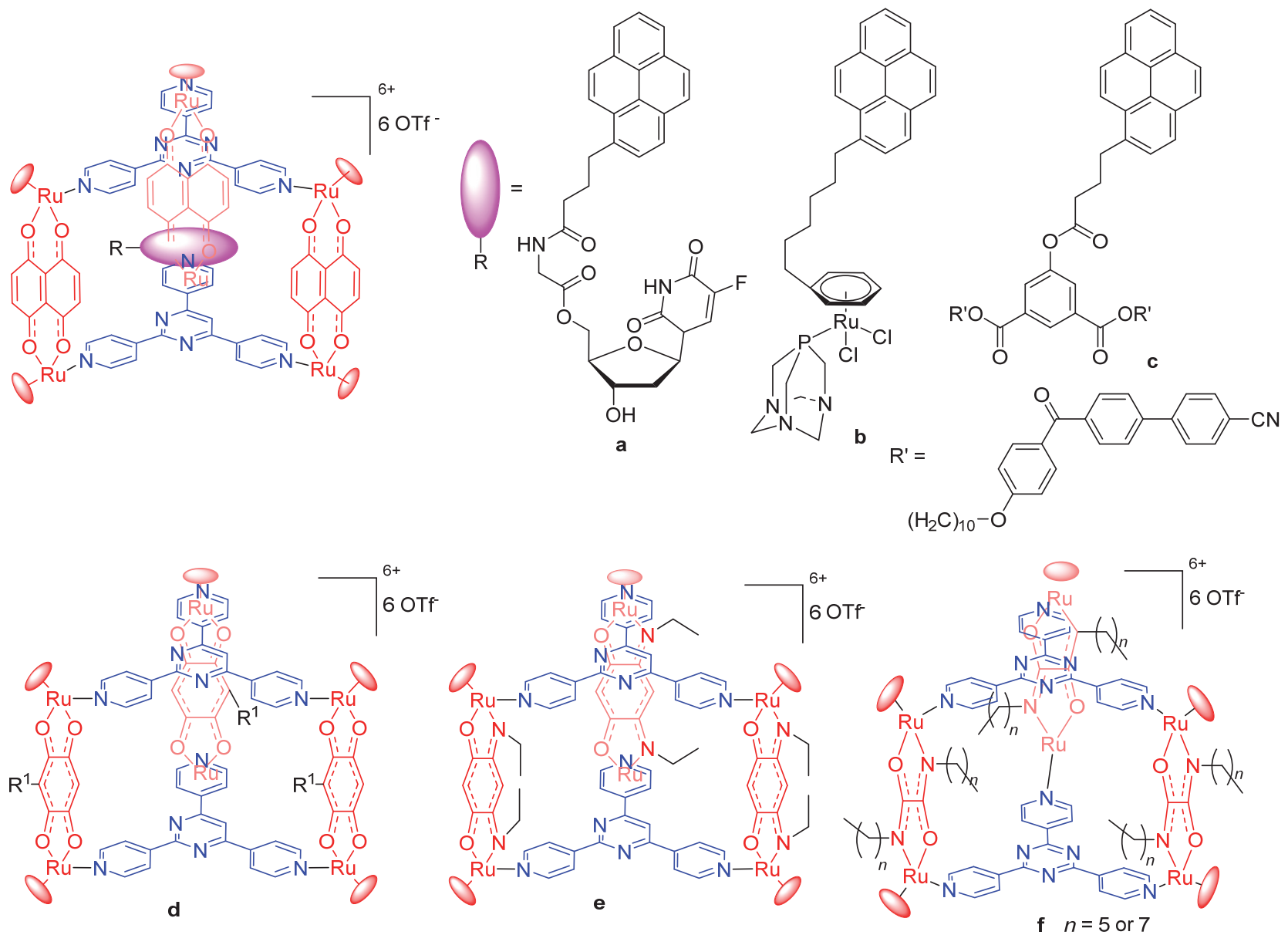

图 13 一系列三棱柱形框架化合物

Figure 13 A series of triangular prism metallacycles

5,8-䒬四甲酸二酰亚胺, 形成一个主体包含三个客体的 主客体体系 ${ }^{[66]}$. 这个复杂的主客体体系也得到了单晶 结构的验证(图 14).

构筑立方体形的八核金属框架化合物也一直是科

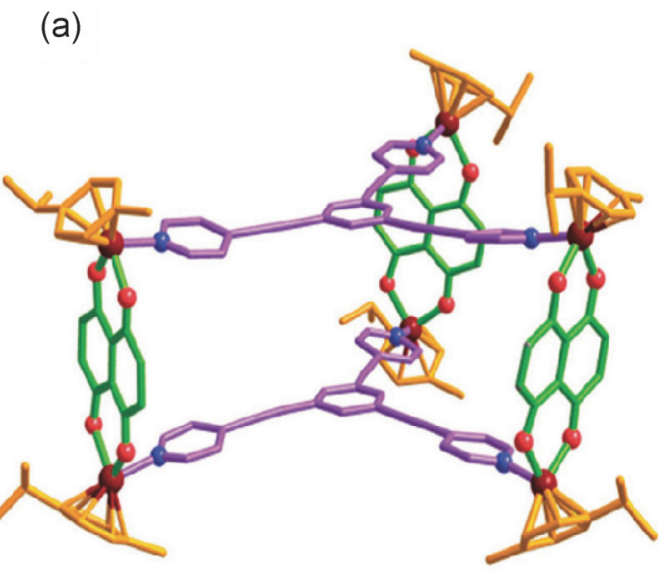

学家的研究兴趣之一. 金国新课题组以吓啉为基础合成 了内消旋化四-(4-吡啶基)-卟啉作为含氮四齿配体, 使 之与双核金属(钉，铱或铑)分子夹，通过 $[2+4]$ 自组装 得到立方体形八核金属框架配合物 ${ }^{[67]}$ (图 15). Barry

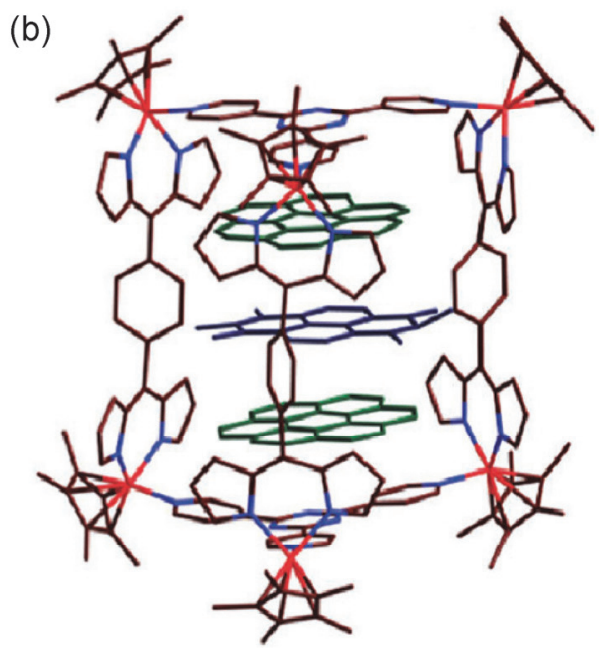

图 14 三棱柱形框架化合物的单晶结构

Figure 14 Single crystal of triangular prism metallacycles 

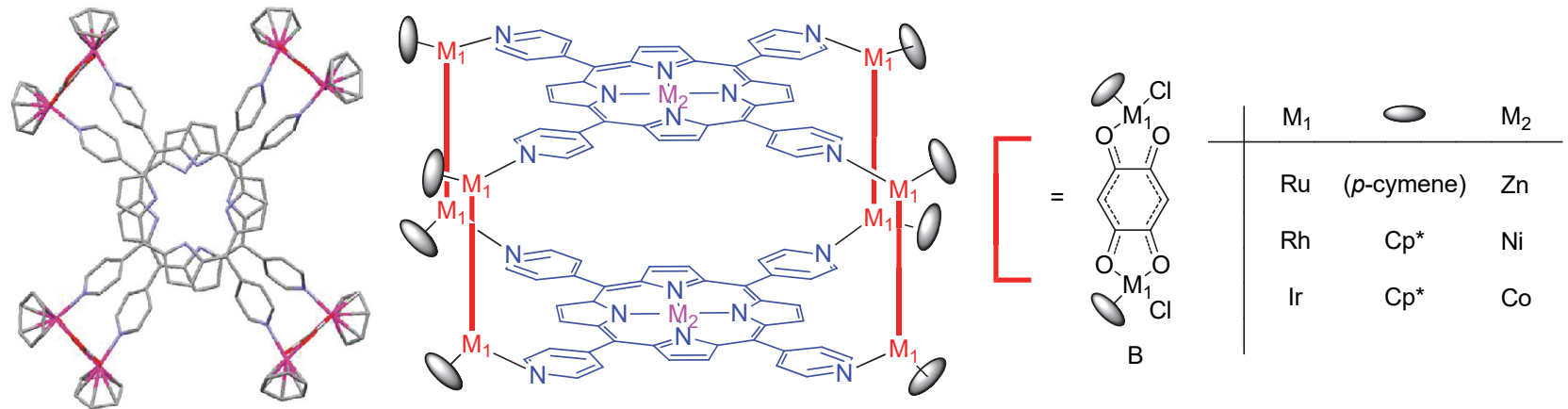

图 15 立方体形框架化合物单晶结构

Figure 15 Single crystal of cubic metallacycles

等 ${ }^{[68,69]}$ 利用杂原子镍(或锌)与卟啉配位后, 与双核金属 钉分子夹自组装得到立方体形异核金属框架化合物. 2017 年, Cook 等 ${ }^{[70]}$ 将钴原子与卟啉配位后, 与双核金属 钉分子夹自组装得到立方体形异核金属框架化合物.

由于三明治夹心结构的金属(钴、铁)络合物具有独 特的同分异构构象, 科学家一直努力使其官能化作为含 氮配体构筑金属框架化合物 ${ }^{[71]} .2017$ 年, Stang 等 ${ }^{[72]}$ 将三 明治夹心结构的钴、铁络合物官能团化引入四个吡啶基, 然后作为四齿含氮配体与双金属钉分子夹通过 $[2+4]$ 自 组装构筑八核金属框架化合物. 当用草酸 $(\mathbf{A})$ 作为分子 夹桥联配体时, 可以顺利得到构筑八核金属框架化合物 (图 16a, 16b). 然而, 用 2,5-二羟基-1,4-苯醌(B)作为分子

(a)

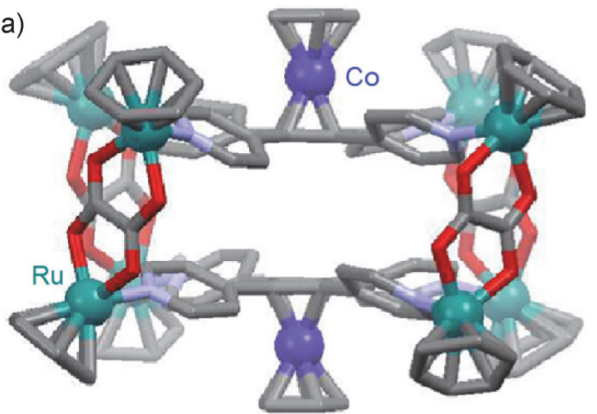

(c)

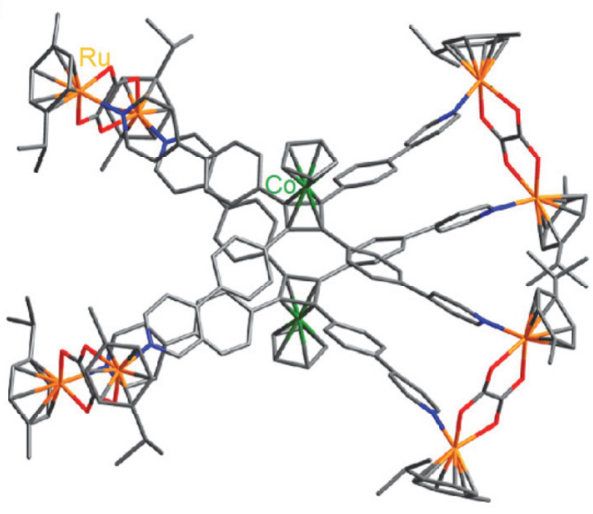

夹桥联配体时，并没有得到理想的八核金属框架化合 物. 由此得出：双金属分子夹的长宽比可能影响自组装 产物的结构.

2018 年, Chi 等 ${ }^{[73]}$ 在钴络合物与吡啶间加入了苯基, 延长了含氮配体的长度，扩大了八核金属框架配合物的 空腔(图 16c，16d). 当用 5,8-二羟基-1,4-菜醌(B)作为分 子夹桥梁配体时，作者没有得到单晶结构，而用草酸盐 作为分子夹桥梁配体顺利地得到了单晶结构, 进一步说 明双金属分子夹的长宽比可能影响自组装过程.

\section{3 超分子拓扑结构(Interlocked)}

近年来, 三叶草结、Solomon 环、Borromean 环、

(b)

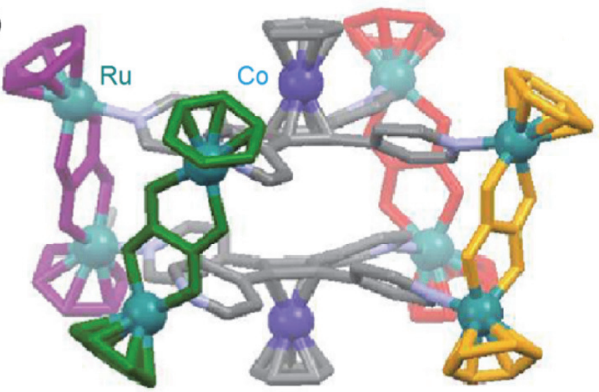

(d)

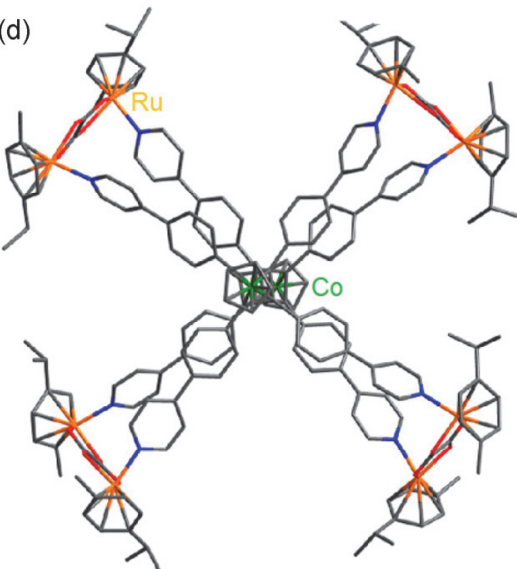

图 16 含三明治夹心结构的立方体形框架化合物单晶结构

Figure 16 Single crystals of cubic metallacycles with sandwich motif 
索烃等具有互锁结构的超分子配合物得到了越来越多 的关注. 这些超分子配合物不仅具有有趣的拓扑结构, 而且拥有作为智能材料的潜在应用价值 ${ }^{[74 ~ 80]}$.

2013 年, 金国新课题组 ${ }^{[81]}$ 利用邻苯双草胺酸根与 二价铜离子配位后与半夹心金属铑前体构建双金属分 子夹, 然后与 $N, N^{\prime}-4$-(二吡啶基)-草酰胺(L8) 和 1,4-双(4-吡啶基)苯(L5)无模板自组装偶然得到三个矩形互相 缠绕的 Borromean 环. 受此激励, 他们改变双金属分子 夹桥梁配体为 1,3-亚丙基双草胺酸根, 也得到了 Borromean 环 ${ }^{[82]}$. 但是, 同种双核金属铑分子夹与 4,4'联吡啶(L2)或 1,4-双(4-吡啶基)乙烯(L3)只得到平面结 构的四核矩形配合物, 而较长的吡啶基桥梁配体更易与 双金属分子夹自组装得到 Borromean 环(图 17).

2017 年, 该小组 ${ }^{[83]}$ 又以二卤代 2,5-二羟基-1,4-苯醌 (B)作为桥联配体构建双金属铱或铑分子夹，与 4,4-二吡 啶基乙炔 (L6) 自组装得到了三个矩形互相缠绕的 Borromean 环(图 18). 不同的卤素原子对 Borromean 环 中单环与单环的相互作用强度有不同的影响, 可以通过 改变卤代原子实现 Borromean 环与单环之间的可逆转 换. 随后, 他们以富电子集团菜二酰亚胺构建双核金属 铑分子夹, 随后与多种双齿含氮配体自组装得到索烃, 而与较长双齿含氮配体得到了 Borromean 环 ${ }^{[84]}$ (图 19). 由此作者得出结论：富电子集团的 $\pi-\pi^{*}$ 相互作用有益于 形成互锁结构的超分子配合物 ${ }^{[85]}$.

Chi 课题组以 6,11-二羟基-5,12-荎并萗二酮作为桥 联配体构建双金属钉、铱分子夹，与吡定基桥梁配体自 组装得到多种拓扑结构的超分子配合物(图 20). 当双金 属钉或铱分子夹与直线型的双齿含氮吡啶基桥梁配体 1,4-双 (4- 吡啶基苯基) 乙炔(L7) 自组装, 可以得到 Borromean 环 ${ }^{[86,87]}$. 当双金属钓分子夹与双齿含氮配体 3,6-双-(4-吡啶基)咔唑自组装, 可以得到 Solomon 环 ${ }^{[88]}$. 当双金属钓分子夹与三齿含氮配体 1,3,5-三-(3-(4-吡啶 基)-1 $H$-吡唑基)苯自组装, 可以得到索烃 ${ }^{[89]}$. 在形成这 些互锁结构的超分子配合物过程中, 富电子芳香平面 6,11 -二羟基- 5,12 -䒺并菜二酮之间的 $\pi-\pi *$ 相互作用起到 了重要作用.

\section{4 总结和展望}

综上所述，我们对半夹心结构的有机金属铱、铑、 钓框架化合物进行了详细论述. 含有半夹心结构的有机 金属铱、铑、钓基元可根据含氮配体的不同，自组装得 到 2-D 平面、3-D 立体或超分子拓扑结构的超分子框架 化合物，且桥联配体可以影响超分子配合物构象及空腔 尺寸．这些不同尺寸的超分子框架化合物在小分子吸 附、生物学应用、智能材料等方面都有潜在应用.
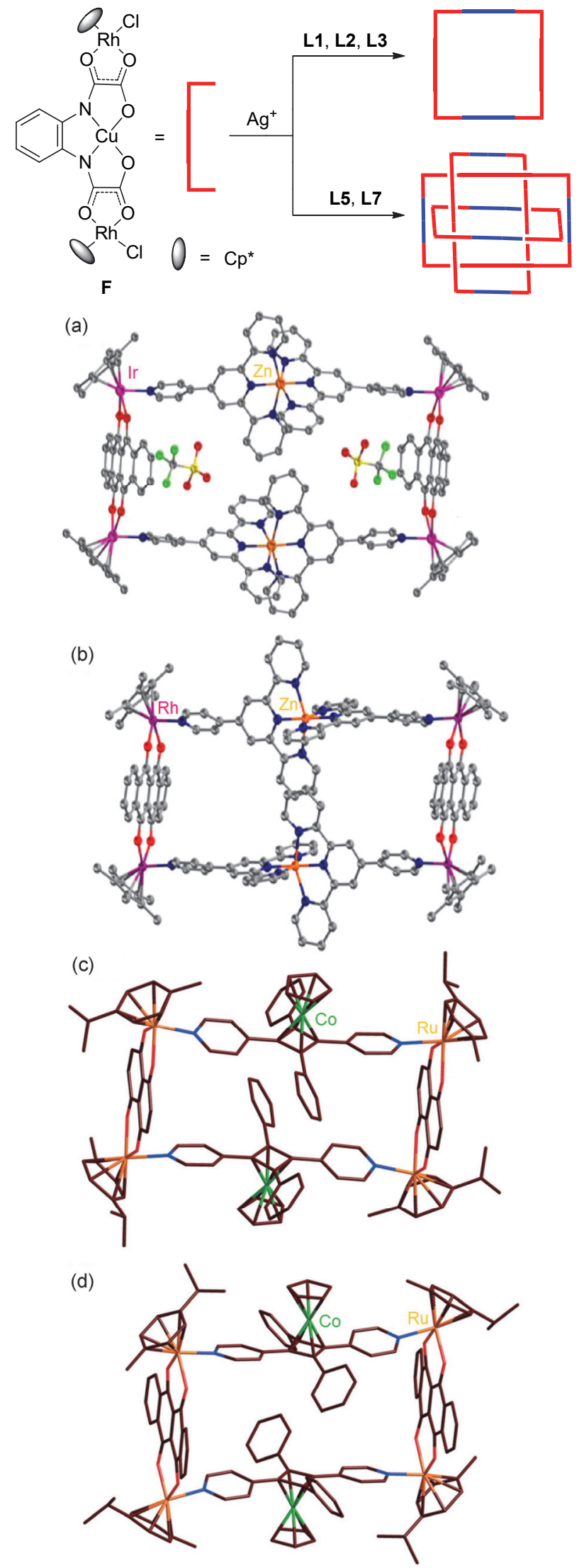

图 17 含铜原子的 Borromean 环合成步骤及单晶结构 Figure 17 Synthesis and single crystals of Borromean metallacycles with $\mathrm{Cu}$ atom 

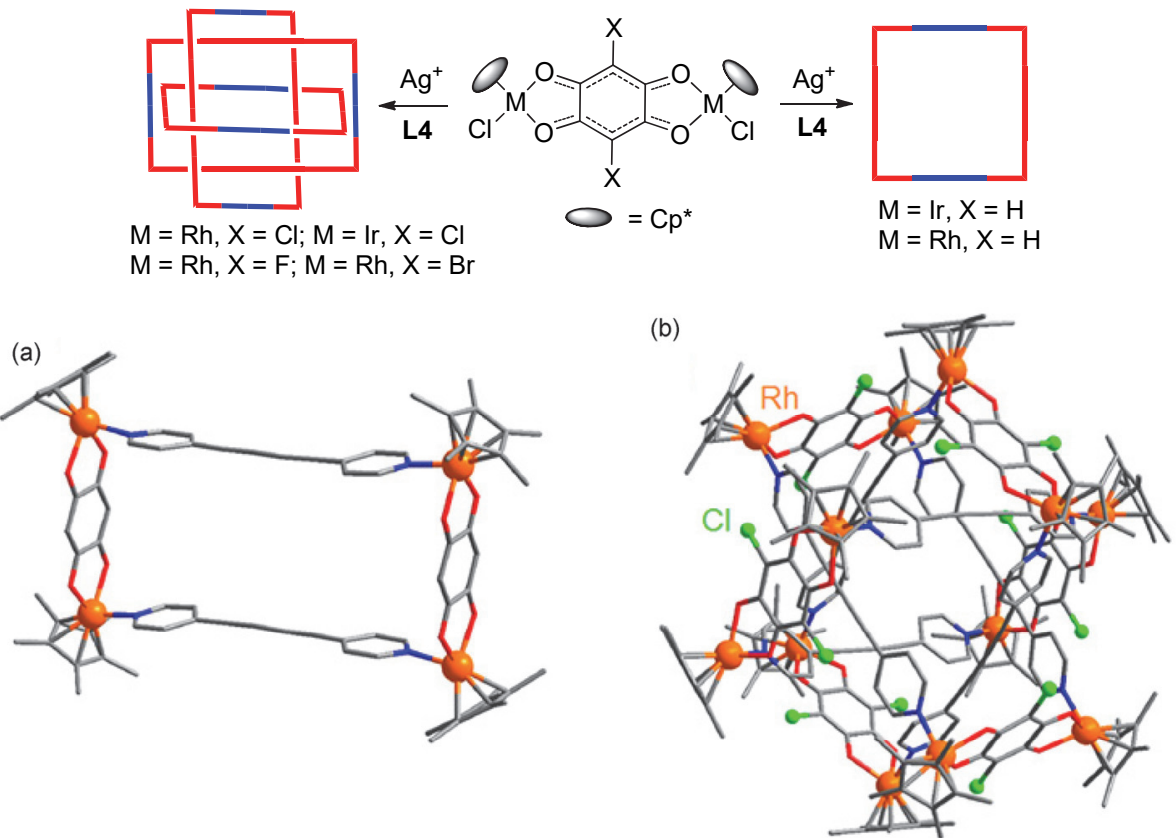

图 18 基于卤代苯醌构筑的 Borromean 环合成步骤及单晶结构

Figure 18 Synthesis and single crystals of Borromean metallacycles with halogenated benzoquinone
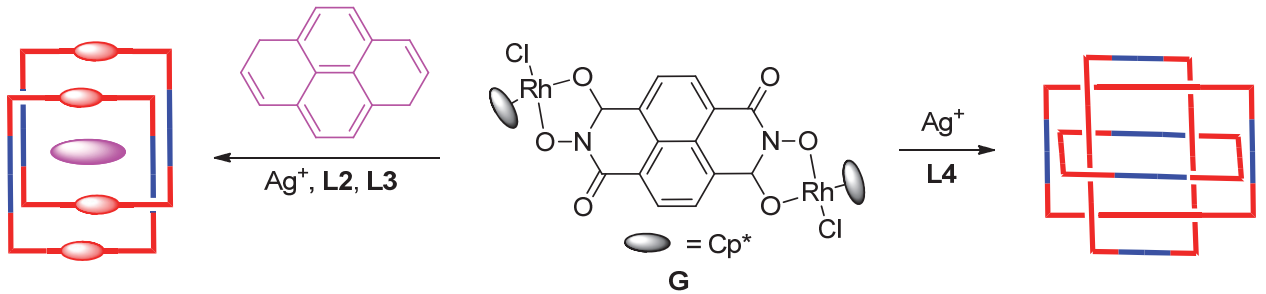

(a)

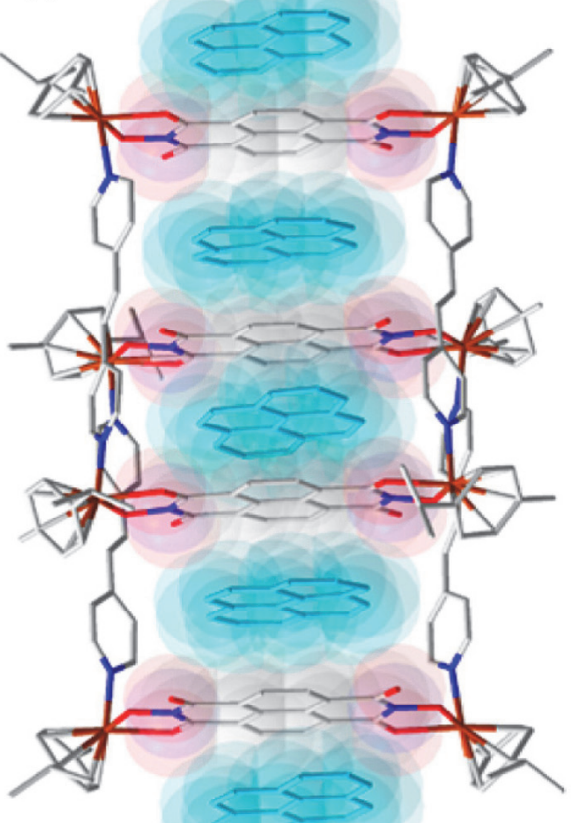

(b)

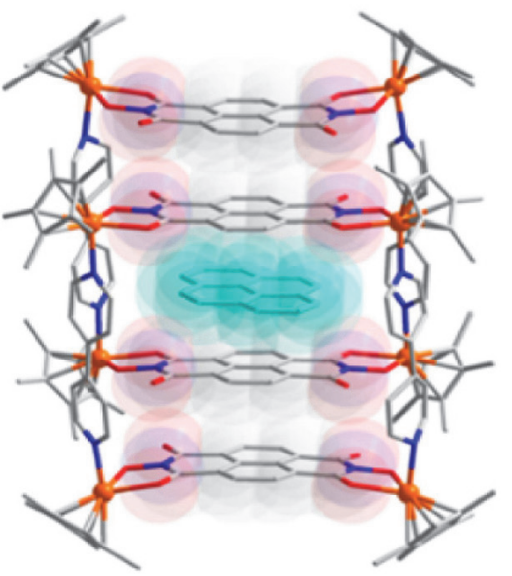

(c)

图 19 索烃和 Borromean 环的合成步骤及单晶结构

Figure 19 Synthesis and single crystals of Borromean metallacycles and catenanes 

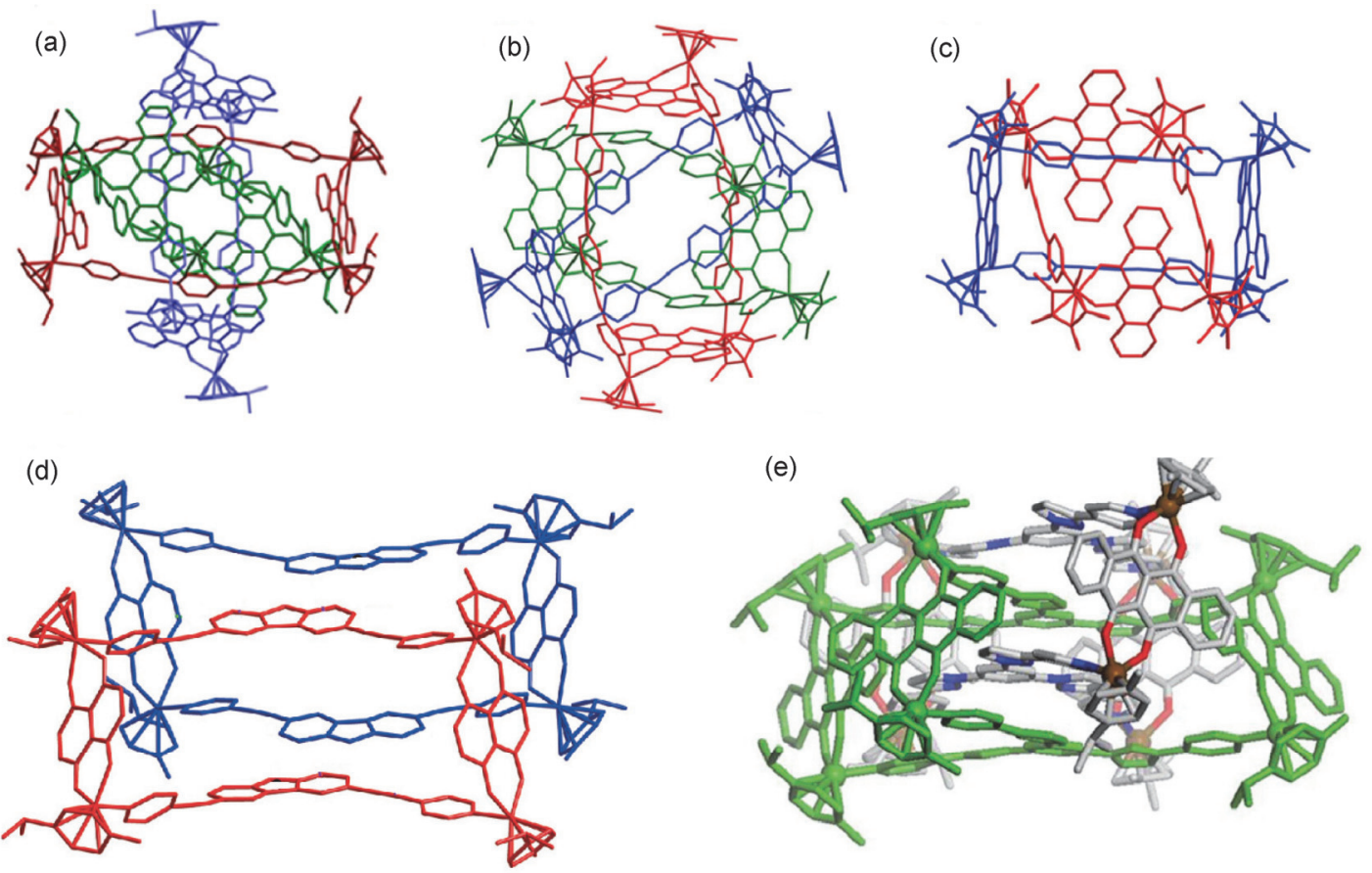

图 20 Borromean 环和索烃的单晶结构

Figure 20 Single crystals of Borromean metallacycles and catenanes

但是，现阶段基于半夹心结构的有机金属铱、铑、 钉框架化合物的研究主要侧重于有机金属框架化合物 的设计与合成. 其应用仍然处于起步阶段, 因此可以期 许该类化合物在以下几个方面的研究取得进一步突破: (i)利用超分子框架化合物选择性捕获、储存、释放碳氢 化合物; 为其在能源材料的开发中提供一定理论依据. (ii)开发超分子框架化合物作为靶向抗癌药物进入体内, 并在癌变部位缓释达到治疗的目的. (iii)设计合成异核 金属(或多金属)框架化合物，利用金属间的协同效应进 行连续催化反应, 从而实现高效的类酶催化(仿生催化) 是值得深入研究的新颖方向.

\section{References}

[1] Swiegers, G. F.; Malefetse, T. J. Chem. Rev. 2000, 100, 3483.

[2] Thomas, J. A. Chem. Soc. Rev. 2007, 36, 856.

[3] Holliday, B. J.; Mirkin, C. A. Angew. Chem., Int. Ed. 2001, 40, 2022.

[4] Gianneschi, N. C.; Masar, M. S.; Mirkin, C. A. Acc. Chem. Res. 2005, 38, 825

[5] James, S. L. Chem. Soc. Rev. 2003, 32, 276.

[6] Yoon, M.; Srirambalaji, R.; Kim, K. Chem. Rev. 2012, 112, 1196.

[7] Chakrabarty, R.; Mukherjee, P. S.; Stang, P. J. Chem. Rev. 2011, 111,6810 .

[8] Pluth, M. D.; Raymond, K. N. Chem. Soc. Rev. 2007, 36, 161.

[9] Yoshizawa, M.; Klosterman, J. K.; Fujita, M. Angew. Chem., Int. Ed. 2009, 48, 3418.

[10] Pluth, M. D.; Bergman, R. G.; Raymond, K. N. Acc. Chem. Res. 2009, 42, 1650 .

[11] Koblenz, T. S.; Wassenaar, J.; Reek, J. N. H. Chem. Soc. Rev. 2008, $37,247$.

[12] (a) Harris, K.; Fujita, D.; Fujita, M. Chem. Commun. 2013, 49, 6703 . (b) Ma, L.-L.; An, Y.-Y.; Sun, L.-Y.; Wang, Y.-Y.; Hahn, F. E.; Han, Y.-F. Angew. Chem., Int. Ed. 2019, 58, 3986.

(c) Wang, Y.-S.; Feng, T.; Wang, Y.-Y.; Hahn, F. E.; Han, Y.-F. Angew. Chem., Int. Ed. 2018, 57, 15767.

(d) Sun, L.-Y.; Sinha, N.; Yan, T.; Wang, Y.-S.; Tan, T. T. Y.; Yu, L.; Han, Y.-F.; Hahn, F. E. Angew. Chem., Int. Ed. 2018, 57, 5161.

(e) Gan, M.-M.; Liu, J.-Q.; Zhang, L.; Wang, Y.-Y.; Hahn, F. E.; Han, Y.-F. Chem. Rev. 2018, 118, 9587.

[13] Cook, T. R.; Zheng, Y. R.; Stang, P. J. Chem. Rev. 2013, 113, 734.

[14] Granzhan, A.; Riis-johannessen, T.; Scopelliti, R.; Severin, K. Angew. Chem., Int. Ed. 2010, 49, 5515.

[15] Forgan, R. S.; Sauvage, J. P.; Stoddart, F. J. Chem. Rev. 2011, 111, 5434.

[16] Fujita, M.; Yazaki, J.; Ogura, K. J. Am. Chem. Soc. 1990, 112, 5645.

[17] Stang, P. J.; Cao, D.-H. J. Am. Chem. Soc. 1994, 116, 4981.

[18] Klausmeyer, K. K.; Rauchfuss, T. B.; Wilson, S. R. Angew. Chem., Int. Ed. 1998, 37, 1694.

[19] Severin, K. Chem. Commun. 2006, 3859.

[20] Han, Y.-F.; Jin, G.-X. Chem. Soc. Rev. 2014, 43, 2799.

[21] Karkas, M. D.; Verho, O.; Johnston, E. V.; Akermark, B. Chem. Rev. 2014, 114, 11863

[22] Yao, Z.-J.; Li, K.; Li, P.; Deng, W. J. Organomet. Chem. 2017, 846, 208.

[23] Thomsen, J. M.; Huang, D. L.; Crabtree, R. H.; Brudvig, G. W. Dalton Trans. 2015, 44, 12452.

[24] Han, Y.-F.; Jia, W.-G.; Yu, W.-B.; Jin, G.-X. Chem. Soc. Rev. 2009, $38,3419$.

[25] Han, Y.-F.; Jin, G.-X. Acc. Chem. Res. 2014, 47, 3571

[26] Zhang, Y.-Y.; Gao, W.-X.; Lin, L.; Jin, G.-X. Coord. Chem. Rev. 2017, 344, 323.

[27] Han, Y.-F.; Lin, Y.-J.; Jia, W.-G.; Weng, L.-H.; Jin, G.-X. Organometallics 2007, 26, 5848 .

[28] (a) Zhang, W.-Z.; Han, Y.-F.; Lin, Y.-J.; Jin, G.-X. Organometallics 2010, 29, 2842.

(b) Gou, X.-X.; Peng, J.-X.; Das, R.; Wang, Y.-Y.; Han, Y.-F. Dalton Trans. 2019, 48, 7236.

(c) Zhang, W.-Y.; Lin, Y.-J.; Han, Y.-F.; Jin, G.-X. J. Am. Chem. 
Soc. 2016, 138, 10700.

[29] Han, Y.-F.; Jia, W.-G.; Lin, Y.-J.; Jin, G.-X. Angew. Chem., Int. Ed. $\mathbf{2 0 0 9}, 48,6234$

[30] Han, Y.-F.; Fei, Y.; Jin, G.-X. Dalton Trans. 2010, 39, 3976.

[31] Han, Y.-F.; Lin, Y.-J.; Jin, G.-X. Dalton Trans. 2011, 40, 10370.

[32] Lin, Y.-J.; Han, Y.-F.; Jin, G.-X. J. Organomet. Chem. 2012, 708, 31.

[33] Zhang, H.-N.; Gao, W.-X.; Deng, Y.-X.; Lin, Y.-J.; Jin, G.-X. Chem. Commun. 2018, 54, 1559 .

[34] Bergamo, A.; Gaiddon, C.; Schellens, J. H. M.; Beijnen, J. H.; Sava, G. J. Inorg. Biochem. 2012, 106, 90.

[35] Rademaker-lakhai, J. M.; Van den Bongard, D.; Pluim, D.; Beijnen, J. H.; Schellens, J. H. M. Clin. Cancer Res. 2004, 10, 3717.

[36] Mari, C.; Pierroz, V.; Ferrari, S.; Gasser, G. Chem. Sci. 2015, 46, 2660.

[37] Schmitt, F.; Govindaswamy, P.; Suss-Fink, G.; Ang, W. H.; Dyson, P. J.; Juillerat-Jeanneret, L.; Therrien, B. J. Med. Chem. 2008, 51, 1811.

[38] Mannancherril, V.; Therrien, B. Inorg. Chem. 2018, 57, 3626.

[39] Mattsson, J.; Govindaswamy, P.; Renfrew, A. K.; Dyson, P. J.; Štěpnička, P.; Süss-Fink, G.; Therrien, B. Organometallics 2009, $28,4350$.

[40] Gupta, G.; Murray, B. S.; Dyson, P. J.; Therrien, B. Materials 2013, $6,5352$.

[41] Liu, J.-J.; Lin, Y.-J.; Jin, G.-X. Organometallics 2014, 33, 1283.

[42] Singh, N.; Jang, S.; Jo, J. H.; Kim, D. H.; Park, D. Y.; Kim, I.; Kim, H.; Kang, S. C.; Chi, K. W. Chem.-Eur. J. 2016, 22, 16157.

[43] Gupta, G.; Das, A.; Ghate, N. B.; Kim, T. H.; Ryu, J. Y.; Lee, J.; Mandal, N.; Lee, C. Y. Chem. Commun. 2016, 52, 4274.

[44] Gupta, G.; Das, A.; Panja, S.; Ryu, J. Y.; Lee, J.; Mandal, N.; Lee, C. Y. Chem.-Eur. J. 2017. 23, 17199.

[45] Wu, T.; Weng, L.-H.; Jin, G.-X. Chem. Commun. 2012, 48, 4435

[46] Guo, B.-B.; Gao, W.-X.; Lin, Y.-J.; Jin, G.-X. Dalton Trans. 2018, $47,7701$.

[47] Han, Y.-F.; Lin, Y.-J.; Jia, W.-G.; Jin, G.-X. Dalton Trans. 2009, 2077.

[48] Han, Y.-F.; Li, H.; Zheng, Z.-F.; Jin, G.-X. Chem.-Asian J. 2012, 7, 1243.

[49] Han, Y.-F.; Jin, G.-X. Chem.-Asian J. 2011, 6, 1348.

[50] Han, Y.-F.; Lin, Y.-J.; Hor, T. S. A.; Jin, G.-X. Organometallics 2012, 31, 995 .

[51] Therrien, B.; Suss-fink, G.; Govindaswamy, P.; Renfrew, A. K.; Dyson, P. J. Angew. Chem., Int. Ed. 2008, 47, 3773.

[52] Yi, J. W.; Barry, N. P. E.; Furrer, M. A.; Zava, O.; Dyson, P. J.; Therrien, B.; Kim, B. H. Bioconjugate Chem. 2012, 23, 461.

[53] Furrer, M. A.; Schmitt, F.; Wiederkehr, M.; Juillerat-Jeanneret, L.; Therrien, B. Dalton Trans. 2012, 41, 7201.

[54] Pitto-barry, A.; Barry, N. P. E.; Zava, O.; Deschenaux, R.; Dyson, P. J.; Therrien, B. Chem.-Eur. J. 2011, 17, 1966.

[55] Therrien, B. CrystEngComm 2015, 17, 484.

[56] Pitto-barry, A.; Zava, O.; Dyson, P. J.; Deschenaux, R.; Therrien, B. Inorg. Chem. 2012, 51, 7119.

[57] Chen, J.; Qiu, X.; Ouyang, J.; Kong, J.; Zhong, W.; Xing, M. Biomacromolecules 2014, 12, 3601.

[58] Minghui, Y.; Fritz, W.; Biprajit, S.; Amine, G.; Pierre, B.; Lucie, R.; Bruno, T. Organometallics 2014, 33, 5043.

[59] Singh, J.; Park, D. W.; Kim, D. H.; Singh, N.; Kang, S. C.; Chi, K. W. ACS Omega 2019, 4, 10810.

[60] Vajpayee, V.; Lee, S.; Kang, S. C.; Cook, T. R.; Kim, H.; Kim, D. W.; Verma, S.; Lah, M. S.; Kim, I. S.; Wang, M.; Stang, P. J.; Chi,
K. W. Dalton Trans. 2013, 42, 466.

[61] Vajpayee, V.; Yang, Y. J.; Kang, S. C.; Kim, C.; Kim, I. S.; Wang, M.; Stang, P. J.; Chi, K. W. Chem. Commun. 2011, 47, 5184.

[62] Wang, M.; Vajpayee, V.; Shanmugaraju, S.; Zheng, Y. R.; Zhao, Z. G.; Kim, H.; Mukherjee, P. S.; Chi, K. W.; Stang, P. J. Inorg. Chem. 2011, 50, 1506.

[63] Vajpayee, V.; Song, Y. H.; Cook, T. R.; Kim, H.; Lee, Y.; Stang, P. J.; Chi, K. W. J. Am. Chem. Soc. 2011, 133, 19646.

[64] Vajpayee, V.; Song, Y.-H.; Jung, Y.-J.; Kang, S.-C.; Kim, H.; Kim, I. S.; Wang, M.; Cook, T. R.; Stang, P. J.; Chi, K. W. Dalton Trans. 2012, 41, 3046.

[65] Vajpayee, V.; Lee, S.; Park, J. W.; Dubey, A.; Kim, H.; Cook, T. R.; Stang, P. J.; Chi, K. W. Organometallics 2013, 32, 1563.

[66] Singh, N.; Jo, J. H.; Song, Y. H.; Kim, H.; Kim, D.; Lah, M. S.; Chi, K. W. Chem. Commun. 2015, 51, 4492.

[67] Han, Y.-F.; Lin, Y.-J.; Weng, L.-H.; Berke, H.; Jin, G.-X. Chem. Commun. 2008, 350.

[68] Barry, N. P. E.; Austeri, M.; Lacour, J.; Therrien, B. Organometallics 2009, 28, 4894.

[69] Barry, N. P. E.; Zava, O.; Dyson, P. J.; Therrien, B. Aust. J. Chem. 2010, 63, 1529.

[70] Oldacre, A. N.; Friedman, A. E.; Cook, T. R. J. Am. Chem. Soc. 2017, 139, 1424

[71] Ryu, J. Y.; Park, Y. J.; Park, H. R.; Saha, M. L.; Stang, P. J.; Lee, J. J. Am. Chem. Soc. 2015, 137, 13018.

[72] Ryu, J. Y.; Wi, E. H.; Pait, M.; Lee, S.; Stang, P. J.; Lee, J. Inorg. Chem. 2017, 56, 5471.

[73] Singh, N.; Singh, J.; Kim, D.; Kim, D. H.; Kim, E. H.; Lah, M. S.; Chi, K. W. Inorg. Chem. 2018, 57, 3521.

[74] Huang, S.-L.; Hor, T. S. A.; Jin, G.-X. Coord. Chem. Rev. 2017, 333,1 .

[75] Ayme, J. F.; Beves, J. E.; Leigh, D. A.; McBuney, R. T.; Rissanen, K.; Schultz, D. Nat. Chem. 2012, 4, 15.

[76] Thorp-greenwood, F. L.; Kulak, A. N.; Hardie, M. J. Nat. Chem. 2015, 7, 526 .

[77] Mcconnell, A. J.; Wood, C. S.; Neelakandan, P. P.; Nitschke, J. R. Chem. Rev. 2015, 115, 7729

[78] Smulders, M. M. J.; Riddell, I. A.; Browne, C.; Nitschke, J. R. Chem. Soc. Rev. 2013, 42, 1728.

[79] Wang, W.; Wang, Y.-X.; Yang, H.-B. Chem. Soc. Rev. 2016, 45, 2656.

[80] Lu, Y.; Lin, Y.-J.; Li, Z.-H.; Jin, G.-X. Chin. J. Chem. 2018, 36, 106.

[81] Huang, S.-L.; Lin, Y.-J.; Hor, T. S. A.; Jin, G.-X. J. Am. Chem. Soc. 2013, 135,8125

[82] Huang, S.-L.; Lin, Y.-J.; Lin, Z.-H.; Jin, G.-X. Angew. Chem., Int. Ed. 2014, 53, 11218 .

[83] Lu, Y.; Deng, Y.-X.; Lin, Y.-J.; Han, Y.-F.; Weng, L.-H.; Lin, Z.-H.; Jin, G.-X. Chem 2017, 3, 110

[84] Zhang, L.; Lin, L.; Liu, D.; Lin, Y.-J.; Lin, Z.-H.; Jin, G.-X. J. Am. Chem. Soc. 2017, 139, 1653.

[85] Lu, Y.; Zhang, H.-N.; Jin, G.-X. Acc. Chem. Res. 2018, 51, 2148.

[86] Kim, T.; Singh, N.; Oh, J.; Kim, E. H.; Jung, J.; Kim, H.; Chi, K. W. J. Am. Chem. Soc. 2016, 138, 8368

[87] Singh, N.; Kim, D.; Kim, D. H.; Kim, E. H.; Kim, H.; Lah, M. S.; Chi, K. W. Dalton Trans. 2017, 46, 571.

[88] Song, Y.-H.; Singh, N.; Jung, J.; Kim, H.; Kim, E. H.; Cheong, H. K.; Kim, Y. Angew. Chem., Int. Ed. 2016, 55, 2007.

[89] Mishra, A.; Dubey, A.; Min, J. W.; Kim, H.; Stang, P. J.; Chi, K. W. Chem. Commun. 2014, 50, 7542. 